Session 3261

\title{
Integration of Liberal Arts, Management, and Technical Skills for Professional Development
}

\author{
Vijay K. Arora \\ Wilkes University
}

\begin{abstract}
Introduction
In the global era of planet Earth moving into trade blocks and multinational organizations, there is a need for Renaissance Engineers - able to integrate science, humanities, and management concepts. This need is creating a paradigm shift to teach design process to solve any problemengineering or non-engineering - as opposed to learning specific solutions to a specific set of problems. Design is a process of decision making in the light of incomplete and often contradictory information. In a course on Professionalism and Ethics-required of all engineers-we challenge students to examine professional and ethical issues by envisioning the future with a follow-up study on the impact of their outcomes on societal, political, and intellectual aspects of professional life. The course emphasizes the Theory of Constraints and Thinking Processes as emphasized in The Goal by Eliyahu Goldratt. The course is consistent with the desired outcomes as listed in ABET Criteria 2000. The course accentuates the importance of adopting holistic thinking comprising higher-order life skills, professional skills, and technical skills. The paper provides an analysis to make education attractive, relevant, and connected to a changing world. The faculty development activities in support of obtaining these outcomes and related motivating factors are also included. The paper concludes with thoughts on the making of an engineering community comprised of professionals with just values of life, liberty and pursuit of happiness for all Earth's inhabitants.
\end{abstract}

\section{Liberal Arts}

The interpretations and definitions of liberal arts are as numerous as the number of institutions and even departments in a given institution. In the light of diversity, it is always a good idea to return to basics. The traditional liberal arts consist of the two components:

- Quadrivium: Arithmetic, Geometry, Astronomy, and Music

- Trivium: Grammar, Rhetoric, and Logic

The first component is more technical in nature while the second involves more human interaction. These were the characteristics of a liberally educated person in ancient civilizations. Modern liberal arts embrace many soft subjects, the choice depends on the politics of one's institution. Due to recent technological advances and global competitiveness, the nature of liberal arts to embrace humans and machines all across the globe is broadening. This is turning engineering into a new liberal art by integrating behavioral factors in the technical curriculum, in true synthesis character of engineering. Businesses in the financial, management, and other information industries are in dire need of engineers who are able to assess trends in industry, e. g., integrated circuit (IC) manufacturing. Even insurance companies need engineers to assess the effects of new technology. 
ABET Criteria 2000 has the spirit of an outcome assessment based on a list of eleven attributes, some of which are of liberal arts/management type. According to a survey of technical employers by Peter Koen at Stevens Institute of Technology, serious gaps exist in preparation of today's engineers. Some of these gaps are:

- Integrity and Honesty

- Knowing how to learn

- Listening

- Responsibility and Self-Management

- Problem Solving
- Decision Making

- Creative Thinking

- Reading

- Oral Communication

- Diversity

In the following, we describe how we integrate liberal arts and management skills in SSE201: Professionalism and Ethics course for professional developement.

\section{Professionalism and Ethics}

The course is required of all engineers in a common section for all. Two books are used for the course. One is a reading book The Goal by Eliyahu M. Goldratt (North River Press). The other book Strategies for Creative Problem Solving by H. Scott Fogler and Steven E. LeBlanc (Prentice-Hall) is used as a textbook to teach the heuristics of problem-solving process. The Goal is taken as a case study to implement the heuristics learned from Strategies for Creative Problem Solving.

In professional development, it is important to present contemporary issues, based on management practices in one's organization. Once, management and business books were disjointed from the technical realities. They were full of philosophical recipes of human interactions and development. In the last few years, the trend has changed. Business books now read like novels and technical ideas are presented with some sense of humor. Dilbert Principle by Scott Adams has been a blockbuster of 1996. This is now followed by Dogbert's Secret Management Handbook. The book describes the workplace where 'incompetent workers are promoted directly to the management without ever passing through the competency stage.' Dilbert Principle's presence in academia stems from the presence of incompetent teachers who are unable to keep pace with the changing technology. They are then shuffled to the management positions to minimize damage to academia. Of course, it creates the maximum damage as their idiocy permeates down to the student level. Such administrators can not make competent decisions for implementing innovations in teaching. Under their power shadow, the learning culture that is supposed to make students work-smart is transforming to that of making them exam-smart under the false pretext of retention.

The Goal is targeted more towards enhancing the throughput of an organization which requires managers to understand the business sense of engineering, especially the manufacturing processes. It is the first book in a sequence of three books, the other two being It's Not Luck and Critical Chain. The series propagates a Socratic method of learning process where there is a dialogue between a teacher and a pupil in the tradition of gurukula (home of the teacher) system practiced in ancient India. The character Jonah-the Guru-Scholar-gives thought processes to 
a plant manger, Al Rogo, to identify bottlenecks (or constraints) as the capacity of the plant can never be greater than the capacity of bottlenecks. Plant Manager's transition from crisis management to the implementations of the Theory of Constraints (TOC) in both his professional and personal life is chronicled. In It's Not Luck, Thinking Processes for conflict management and market segmentation are described. In Critical Chain, shortfalls of executive MBA programs are discussed.

While asked to write a book report on The Goal, the students are asked to support the TOC in shortening the production cycle and problem solving by Thinking Processes by mapping cause and effect relationships and selling the solution to a hostile audience who will not trust you. Students are asked to explain how the TOC and Thinking Processes work equally well in business, politics, and family disputes-offering peace or profit without compromise. In most businesses, pressures mount as managers strive to achieve local optima instead of company wide profits. Students analyze customer's perception of value, design package of benefits addressing true value, and how whole can be greater than the sum of its parts. They show how to eliminate root causes of problems to reach goals by common sense that can often be uncommon.

The topics that are emphasized during this learning process are: Networking, Ethical Decisionmaking, Leadership, Project Management, and others. For ethical cases, we use a video series entitled Ethics in Professional Life used at Carnegie-Mellon University. The assignments ask them to analyze ethical cases based on a VCR framework that includes: Values and Virtues, Consequences and Contingencies, and Rights and Responsibilities. Weekly assignments include essays on topics such as Paradigm Shift, Internet, Technical Management, Communications, Group Dynamics, Alternatives Generation, Expression of the Self, etc. Examples of capstone projects are given under the theme Discovering the Future. Examples are: Re-Conditioned Body Parts, High-Tech Classrooms, Artificial Eyesight for Blind People, Space Colonies, Solar Reflectors, Robotics Games, etc. Students do the feasibility study only.

Some of the outcomes of the course are: Understand the complexity of group dynamics while working as a member of the team to which task is assigned; Organize data in order to get useful information and then put knowledge to make an effective decision; analyze need and economic factors consistent with values of society; generation and evaluation of alternatives; communications to peers and public-at-large; and use of technical resources, e. g., internet.

\section{Faculty Development}

Ed Boyer's Scholarship Reconsidered gives four categories of faculty scholarship: discovery, teaching, application, and integration. Boyer made it clear in his interpretations of these four faculty functions that scholarship is an accent on the four functions and without this accent, all activities are redundant. In professional development of would-be-engineers, faculty development plays a major role. Traditionally, discovery mode of scholarship has been easy to assess and reward. Measurement of scholarship in all four functions is now being heavily emphasized. Many schools are now requiring faculty to build up a portfolio which shows interdependence of all four functions of faculty scholarship.

According to Tom Peters-the management guru-every organization has Brahama-the Creator, Vishnu - the Preserver, and Shiva - the Destroyer. Once an organization is created, Vishnu takes over. In any organization, it is Shiva which has to be protected to destroy obsolete practices so that the renewal takes place. In making a case for renewal process, Stephen Covey 
of The 7 Habits of Highly Effective People strongly advises to move from dependence to independence and to inter-dependence. It is inter-dependence which is highly valued in a world where information travels at the speed of light. This inter-dependence can truly teach us the value of teamwork in a multicultural and multicolored world. A fully functioning global person with a knowledge of the self, the job, the organization, the environment, and the world can very well understand the value of liberal arts and with this develops the power of sound decision making. Service —without a sole motive of reaping fruits here on Earth or in Heaven-is the highest form of professional excellence. Excellence is, therefore, not an act, it is a habit.

\section{Biographical Sketch}

VIJAY K ARORA is Director of Graduate Studies and Professor of Electrical Engineering at Wilkes University. $\mathrm{He}$ is a past chair of the International Division of the American Society for Engineering Education (ASEE). He has held visiting appointments at a number of international institutions and is listed in a number of Who's Who directories. He enjoys the privilege of knowing the cultures and educational methods being practiced around the globe. He has authored or co-authored over 120 papers on scientific, technical, and and educational issues. 